\title{
Sesamin ameliorates mucosal tissue injury of mesenteric ischemia and reperfusion in an experimental rat model
}

\author{
Mustafa B. Sayhan ${ }^{1}$, Serhat Oguz², Ömer Salt ${ }^{1}$, Nuray Can ${ }^{3}$, Taner Ozgurtas ${ }^{4}$, Tulın D. Yalta ${ }^{3}$
}

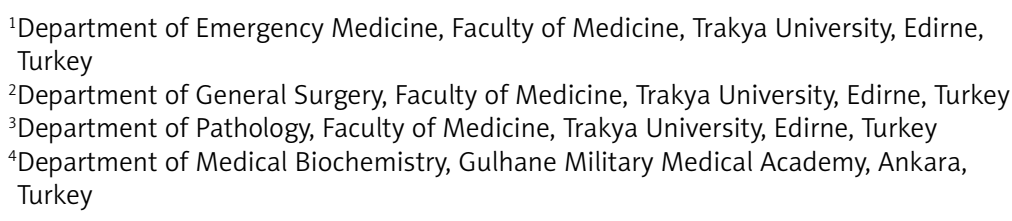

Submitted: 1 March 2017

Accepted: 19 April 2017

Arch Med Sci 2019; 15 (6): 1582-1588

DOI: https://doi.org/10.5114/aoms.2017.68535

Copyright $\odot 2018$ Termedia \& Banach

\section{Abstract}

Introduction: Mesenteric ischemia/reperfusion (I/R) injury is a serious clinical condition. There were a lot of experimental studies performed in the treatment of I/R injury. To our knowledge, this is the first experimental study with effects of sesamin on I/R injury model. We aimed to investigate the protective effect of sesamin on mesenteric I/R injury model.

Material and methods: A total of 32 male Sprague-Dawley rats were divided into four groups. Control group: superior mesenteric artery (SMA) exposed without clamping. I/R group: SMA was clamped for $60 \mathrm{~min}$ and then reperfused for $2 \mathrm{~h}$. Sesamin group (S): $30 \mathrm{mg} / \mathrm{kg}$ sesamin were given for 5 days, and SMA exposed without clamping. I/R + S group: $30 \mathrm{mg} / \mathrm{kg}$ sesamin were given for 5 days, SMA was clamped for $60 \mathrm{~min}$, and then reperfused for $2 \mathrm{~h}$. Plasma and tissue oxidant parameters were investigated as well as histopathological evaluation.

Results: Plasma and tissue total antioxidant status (TAS) levels were significantly higher in I/R $+\mathrm{S}$ group compared to the rest $(p<0.005)$. The plasma TAS levels in I/R group was significantly low. The highest tissue TAS levels were detected in I/R + S group. The high levels of plasma and tissue TOS were found in I/R + S group. Plasma and tissue OSI levels were significantly higher in I/R group. Histopathologic evaluation showed that the mean level of intestinal tissue injury score in I/R group was 2.75 and 1.38 in I/R + S group.

Conclusions: Sesamin helps to protect the intestinal tissue at the cellular level by reducing the oxidative stress and inflammation at both the plasma and tissue levels in the experimental I/R model.

Key words: mesenteric ischemia reperfusion, sesamin, oxidant parameters, rat.

\section{Introduction}

Intestinal ischemia is a serious disease of gastrointestinal system and can be seen in all age groups. It has some specific forms for each age group [1]. For example, necrotizing enterocolitis is mostly seen in neonates, while intestinal volvulus is mostly seen in elders [2]. There are varying levels of tissue damage, which proceed to intestinal ischemia [3].

\author{
Corresponding author: \\ Prof. Mustafa B. Sayhan \\ Department of Emergency \\ Medicine \\ Faculty of Medicine \\ Trakya University \\ 22300 Edirne, Turkey \\ Phone: +90 5327000095 \\ E-mail: mustafaburak@ \\ yahoo.com
}


All these types of damage are related to decreased blood flow towards the intestine. In adult population, there are many etiological factors of intestinal ischemia such as acute mesenteric ischemia, sepsis, and strangulated hernia [4, 5]. The most important point to prevent intestinal ischemia is restoring the blood flow [6]. However, after reperfusion of ischemic tissue, clinicians face another serious problem called 'ischemia-reperfusion (I/R) injury'. This clinical condition is generally observed in arterio-venous occlusion of gastrointestinal tract [3]. This situation results with an inflammatory process that includes mucosal damage, activation, and infiltration of neutrophils as well as activation of complement system and further mucosal injury after reperfusion process [7]. Toxic oxygen metabolites are yet other factors that are responsible for tissue damage [8], and probably, the most sensitive visceral organ to I/R is the small intestine [9]. Protecting the visceral organs from I/R injury is as important as treatment of primary pathology.

As a member of pedaliaceae family, sesame (sesamum indicum l.) was firstly cropped in Babylon over 4,000 years ago, and it has an ancient history [10]. Sesame seed oil (SSO) has been used in diet for almost 2,000 years [11]. It is shown that SSO has the longest oxidative stability time (92 h) among dietary oils [12]. There are also other studies that investigated antioxidative, anti-inflammatory, neuro, and chondroprotective effects of SSO [13-15]. As an important component of SSO, sesamin is investigated in terms of its oxidative stress attenuation, and it was showed that sesamin has a protective effect against oxidative stress [16]. In this study, plasma and tissue total oxidative and antioxidant status (TAS) levels were evaluated by a novel automated measurement method that was developed by Erel [17, 18].

There were a lot of experimental studies performed in terms of treatment of I/R injury. However, no study regarding the attenuation of mesenteric I/R injury by sesamin is available in the literature. To our knowledge, this is the first experimental study with sesamin on mesenteric ischemia reperfusion model. In this study, we aimed to investigate whether sesamin has a protective effect on mesenteric I/R injury in a rat model using histopathologic evaluation and measuring oxidant parameters such as total antioxidant status (TAS), total oxidative status (TOS), and oxidative stress index (OSI) of the plasma and tissue samples of rats.

\section{Material and methods}

\section{Animals and experimental design}

This study was performed in accordance with the National Institutes of Health guidelines for the use of experimental animals after approval of the local animal ethics committee and conducted at the Laboratory Animals Care Unit of Trakya University, Edirne, Turkey (Permission No: TUHDYEK-2011/80).

A total of 32 male Sprague-Dawley rats aged 6 to 8 weeks and weighing $290 \pm 320 \mathrm{~g}$ were used for the study. Rats were housed in a light controlled room with a 12-hour light/dark cycle and were allowed free access to food and water. They were randomly assigned into 4 groups, with the use of a computer-generated table. Each group consisted of 8 rats as below:

- Control group (group C, $n=8$ ): After an overnight fast, rats were operated and superior mesenteric artery (SMA) was exposed without any clamping.

- Ischemia/reperfusion group (group I/R, $n=8$ ): After an overnight fast, rats were operated, SMA was exposed and clamped for $60 \mathrm{~min}$, and then reperfused for $2 \mathrm{~h}$.

- Sesamin group (group S, $n=8$ ): In addition to food and water, $30 \mathrm{mg} / \mathrm{kg}$ sesamin were given via orogastric tube for 5 days, and after an overnight fast, rats were operated and SMA was exposed without any clamping.

- Ischemia reperfusion + sesamin group (group I/R + S, $n=8)$ : In addition to food and water, $30 \mathrm{mg} / \mathrm{kg}$ sesamin were given via orogastric tube for 5 days, and after an overnight fast, rats were operated and SMA was exposed and clamped for $60 \mathrm{~min}$, and then reperfused for $2 \mathrm{~h}$. Sesamin was purchased from the Bulk Nutrients Pure Supplements (Australia). Anesthesia was achieved by intramuscular administration of 10 mg/kg of xylazine (Rompun ${ }^{\circledR}$, Bayer llac Sanayi, Istanbul, Turkey) and $50 \mathrm{mg} / \mathrm{kg}$ of ketamine hydrochloride (Ketalar ${ }^{\circledast}$, Eczacibasi Ilac San, Istanbul, Turkey). Abdomen of each rat was shaved and then disinfected with $10 \%$ povidone iodine solution (Isosol ${ }^{\circledR}$, Merkez Laboratory, Ilac San, Istanbul, Turkey). Laparotomy was performed through a $3 \mathrm{~cm}$ midline incision using sterile technique. In the groups of $C$ and S, SMA was isolated but not occluded. Blood and tissue samples were collected from these groups and then the animals were sacrificed. In the groups of $I / R$ and $I / R+S, S M A$ was occluded with an atraumatic microvascular bulldog clamp with car for 60 min. Mesenteric ischemia was confirmed by observing intestinal paleness and loss of mesenteric pulsations. After $60 \mathrm{~min}$, the clamp was removed, mesenteric artery pulsation was observed, and the intestine reperfused for $120 \mathrm{~min}$. In order to prevent from hypothermia, the operation area was covered with a warm moist dressing.

At the end of the $3 \mathrm{~h}$, cardiac blood and intestinal tissue samples were obtained from $5 \mathrm{~cm}$ proximal of the ileocecal region from small intestine. 
The bowel specimens of animals were harvested for biochemical analysis.

\section{Biochemical evaluation}

Plasma of the blood samples was separated from the cells by centrifugation (Hettich Lab Technology ${ }^{\circledR}$, Tuttlingen, Germany) at 3,000 $\times$ g for $10 \mathrm{~min}$ and stored at $-80^{\circ} \mathrm{C}$ until analysis. Serum TOS and TAS were assessed using an automated measurement method, as described previously $[17,18]$.

The results are expressed as mmol Trolox ${ }^{\oplus}$ (6-hydroxy-2, 5, 7, 8-tetramethylchroman-2-carboxylic acid) equivalents/l for TAS and micro-molar hydrogen peroxide equivalents per liter $(\mathrm{mmol}$ $\mathrm{H}_{2} \mathrm{O}_{2}$ equivalents/l) for TOS.

The OS index (OSI) is defined as the ratio of the TOS to TAS level, expressed as a percentage. In order to calculate it, TAS units were changed to $\mathrm{mmol} / \mathrm{l}$, and the OSI value was defined as: OSI (arbitrary units $)=$ TOS $\left(\mu \mathrm{mol} \mathrm{H}_{2} \mathrm{O}_{2}\right.$ equivalents/l)/TAS (mmol Trolox ${ }^{\circledast}$ equivalents/l) [19].

\section{Histopathological evaluation}

After all the rats were sacrificed, small intestine samples were taken from $5 \mathrm{~cm}$ proximal of ileocecal valve, washed with normal saline, and then placed in $10 \%$ neutral formaldehyde before staining. Subsequently, after $24 \mathrm{~h}$ fixation, all tissues were paraffinized, and $5 \mu \mathrm{m}$ sections were sliced for hematoxylin and eosin staining. After staining, all tissues were evaluated histopathologically with a mark of Nicon Eclips E80i optic microscope. Histopathological evaluation was performed by a pathologist who was blinded to the study design, by using scoring system described by Chiu et al. [20]. In this scoring system, numbering from 0 to 5 is used according to the level of mucosal damage (Table I).

\section{Statistical analysis}

Statistical analysis of the study was performed using SPSS (Statistical Package for Social Scienc- es, Chicago, IL) 20.0 program. The results were expressed as mean \pm standard deviation. The Kruskal-Wallis test was used for multiple group comparisons, and the Mann-Whitney $U$ test for comparing groups to each other. A value of $p<0.05$ was considered statistically significant.

\section{Results}

\section{Plasma TAS, TOS and OSI}

When the groups were compared to each other in terms of plasma TAS levels, statistically significant differences were found among all groups ( $p=$ 0.001). Plasma TAS levels were significantly higher in the I/R $+S$ group compared to the rest (group $C, I / R, S ; p<0.005)$. The levels of plasma TAS in I/R group compared with the $S$ and I/R $+S$ groups were found to be significantly lower $(p<0.005)$. In addition, the plasma TAS levels were significantly higher in the sesamin application group than the control group ( $p<0.005$; Table II).

Plasma TOS levels were significantly different among the $\mathrm{C}, \mathrm{S}, \mathrm{I} / \mathrm{R}$, and I/R $+\mathrm{S}$ groups $(p=0.002)$. Also, plasma TOS levels in the $I / R$ group were significantly higher than in the $C, S$, and $I / R+S$ groups $(p<0.005)$. The high levels of plasma TOS were found in the $I / R+S$ group compared with those in the $S$ group $(p<0.005)$.

When the groups were compared to each other in terms of plasma OSI index levels, statistically significant differences were found among all groups ( $p=0.001)$. Plasma OSI levels were significantly higher in the I/R group than in the $C, S$, and I/R $+\mathrm{S}$ groups $(p<0.005$; Table II).

\section{Tissue TAS, TOS and OSI}

Tissue TAS levels were significantly different among the $C, S, I / R$, and $I / R+S$ groups $(p=0.002)$. The highest tissue TAS levels were detected in the group I/R + S compared to the rest (group C, S, I/R; $p<0.005)$. In addition, the tissue TAS levels were significantly higher in the sesamin application group $\mathrm{S}$ than the control group $(p<0.005)$.

Table I. Intestinal tissue damage assessment scale as defined by Chiu et al.

\begin{tabular}{|c|c|}
\hline Level & Microscopic findings \\
\hline 0 & No mucosal changes \\
\hline 1 & $\begin{array}{c}\text { Despite Grunhagen changes in subepithelial region, villous structures are preserved and no cellular } \\
\text { damage or inflammation }\end{array}$ \\
\hline 2 & $\begin{array}{c}\text { Lysis at cellular level, increase in gap between villous structures, and formation of Grunhagen in } \\
\text { subepithelial region }\end{array}$ \\
\hline 3 & Destruction of free villous structures, dilation at capillary level and inflammation at cellular level \\
\hline 4 & $\begin{array}{c}\text { Inflamed cells, necrotic material, bleeding, and ulceration due to near-total destruction of the villous } \\
\text { structures }\end{array}$ \\
\hline 5 & $\begin{array}{l}\text { No visible structure other than amorphous material in the submucosal tissue and the entirely destroyed } \\
\text { mucous membrane }\end{array}$ \\
\hline
\end{tabular}


Table II. Serum TAS, TOS, and OSI levels of the groups, mean \pm SD (median)

\begin{tabular}{|lccccc|}
\hline Parameter & \multicolumn{5}{c|}{ Group $(n=8)$} \\
\cline { 2 - 6 } & $\mathbf{C}$ & $\mathbf{S}$ & $\mathrm{I} / \mathrm{R}$ & I/R $+\mathbf{S}$ & $P$-value \\
\hline TAS [mmol/l] & $1.9 \pm 0.2(1.88)$ & $2.3 \pm 0.3^{2}(2.3)$ & $2.1 \pm 0.4^{1}(2.1)$ & $2.8 \pm 0.3^{3}(2.82)$ & 0.001 \\
\hline TOS [mmol/l] & $21.4 \pm 6.3(21.5)$ & $18.2 \pm 5.1(18.3)$ & $96.8 \pm 28.7^{4}(98.9)$ & $25.6 \pm 6.5^{5}(25.2)$ & 0.002 \\
\hline OSI [arbitrary units] & $11.2 \pm 3.6(11.2)$ & $7.9 \pm 2.8(7.9)$ & $46.1 \pm 15.2^{6}(46.8)$ & $9.1 \pm 3.2(8.7)$ & 0.001 \\
\hline
\end{tabular}

$S D$ - standard deviation, $C$ - control, $S$ - sesamin, $I / R$ - ischemia/reperfusion, $I / R+S-i$ schemia reperfusion + sesamin, TAS - total antioxidant status, TOS - total oxidative status, OSI - oxidative stress index, $P$-values indicate the differences between the groups (Kruskal-Wallis test), $\left.{ }^{1} I / R\left\langle S, I / R+S,{ }^{2} S>C,{ }^{3} I / R+S\right\rangle C, S, I / R,{ }^{4} I / R\right\rangle C, S, I / R+S,{ }^{5} I / R+S>S,{ }^{6} I / R>C, S, I / R+S$ (Mann-Whitney U test, $p<0.005)$.

Table III. Tissue TAS, TOS, and OSI levels of the groups, mean \pm SD (median)

\begin{tabular}{|lccccc|}
\hline Parameter & \multicolumn{5}{c|}{ Group $(n=8)$} \\
\cline { 2 - 6 } & $\mathrm{C}$ & $\mathrm{S}$ & $\mathrm{I} / \mathrm{R}$ & $\mathrm{I} / \mathrm{R}+\mathrm{S}$ & $P$-value \\
\hline TAS [mmol/I] & $2.7 \pm 0.4(2.8)$ & $3.6 \pm 0.2^{2}(3.6)$ & $2.9 \pm 0.3(2.9)$ & $3.9 \pm 0.2^{1}(3.9)$ & 0.002 \\
\hline TOS [mmol/I] & $86.8 \pm 9.7(87.3)$ & $26.2 \pm 9.3(26.1)$ & $218.4 \pm 79.3^{3}(219.5)$ & $105.8 \pm 25.6^{4}(107.3)$ & 0.004 \\
\hline OSI [arbitrary units] & $32.1 \pm 4.2(32.9)$ & $7.3 \pm 3.4(7.3)$ & $75.3 \pm 21.8^{5}(74.7)$ & $27.1 \pm 8.4(26.9)$ & 0.003 \\
\hline
\end{tabular}

SD - standard deviation, $C$ - control, $S$ - sesamin, I/R - ischemia/reperfusion, $I / R+S$ - ischemia reperfusion + sesamin, TAS - total antioxidant status, TOS - total oxidative status, OSI - oxidative stress index, $p$-values indicate the differences between the groups (Kruskal-

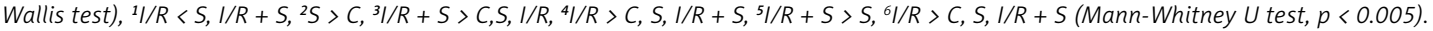

Tissue TOS levels were significantly different among the $\mathrm{C}, \mathrm{S}, \mathrm{I} / \mathrm{R}$, and $\mathrm{I} / \mathrm{R}+\mathrm{S}$ groups $(p=0.004)$. The highest tissue TOS levels were detected in the group I/R compared to the other groups (group C, $\mathrm{S}, \mathrm{I} / \mathrm{R}+\mathrm{S} ; p<0.005)$. In addition, the tissue TOS levels were significantly higher in $\mathrm{I} / \mathrm{R}+\mathrm{S}$ group compared to group S $(p<0.005)$.

When the groups were compared to each other in terms of tissue OSI levels, statistically significant difference was found among all groups $(p=0.003)$. Tissue OSI levels were significantly higher in the I/R group, than the $C, S$, and I/R + S groups ( $p<0.005$; Table III).

\section{Histopathologic evaluation}

Histopathologic evaluation showed that the levels of mucosal damage in all rats in the control and sesamin application group $\mathrm{S}$ were 0 . No mucosal injury was observed in both groups (Figure $1 \mathrm{~A}$ ). It was determined that 3 rats in the I/R group had level 2 mucosal damage (Figure $1 \mathrm{C}$ ), 2 had level 3 mucosal damage (Figure 1 D), 2 had level 4 mucosal damage (Figure $1 \mathrm{E}$ ), and 1 had level 5 mucosal damage (Figure $1 \mathrm{~F}$ ). The mean level of intestinal tissue injury score in this group was 2.75. The mean intestinal tissue injury score of the group $\mathrm{I} / \mathrm{R}+\mathrm{S}$ was $1.38 ; 5$ rats in this group had level 1 mucosal damage (Figure $1 \mathrm{~B}$ ) and 3 had level 1 mucosal damage, and it was significantly lower than I/R group $(p<0.005)$ (Tables IV and V).

\section{Discussion}

Because of the high oxygen requirement, the small intestines are highly sensitive to free radi- cals and the free oxygen radicals they cause [21]. Ischemia and mucosal cell death occur in the intestinal mucosa after vascular problems. Even if the ischemic tissue ischemia is again reperfused, degeneration and damage of the mucosal villi continue due to the free oxygen radicals that are present $[22,23]$. These free radicals are quite unstable and easily turn into hydrogen and hydrogen peroxide, and cause oxidative damage of cells and tissues [24]. It is very important to prevent damage after reperfusion in terms of maintaining the vitality of the tissue, despite the fact that tissue ischemia cannot be prevented.

Detection of total antioxidant level is a very useful method in determining the organism's protective capacity against oxygen free radicals. Similarly, the total oxidative status is used to determine the oxidative power of free radicals in the organism [25]. However, these markers have been measured only from serum until now. In our study, tissue TAS and TOS levels were measured in addition to plasma TAS and TOS levels, unlike other studies. In this way, we aimed to determine the levels of TAS and TOS at tissue level.

Despite the fact that studies on mesenteric ischemia reperfusion injury treatment have been performed with many agents in the literature, no study on the effect of sesamin on mesenteric ischemia reperfusion injury has been seen [26-28]. In a study conducted by Torun et al., it has been shown that TAS, TOS, and OSI values may not only be an indication of oxidative or antioxidative status but may also be used to evaluate treatment response [29, 30]. In our study, these parameters were measured at the tissue level in addition to 

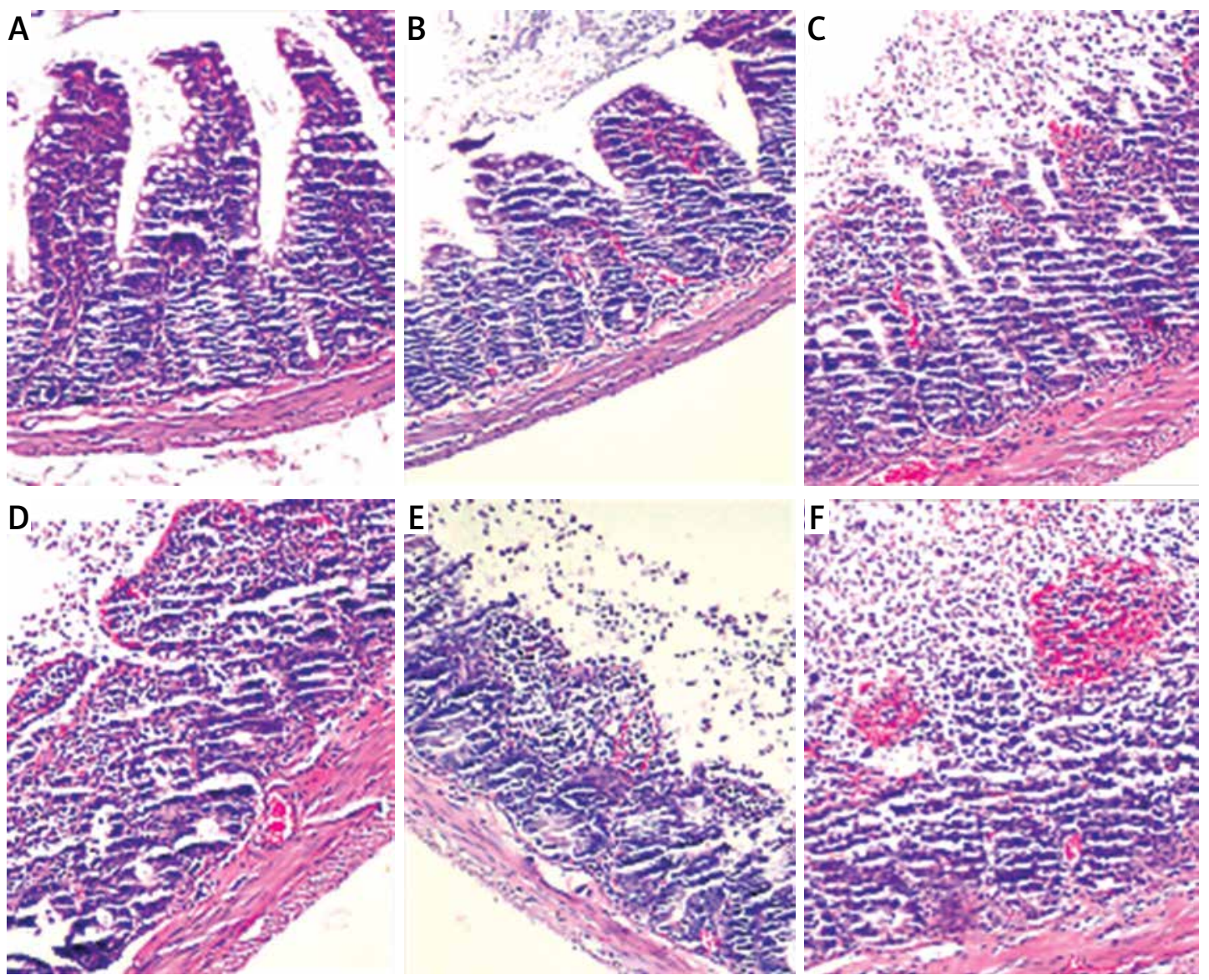

Figure 1. Microscopic appearance of Chiu score (intestinal tissue injury score) (H \& E, 200x). A - score 0, B - score 1 , C-score 2, D-score 3, E-score 4, F-score 5

Table IV. Intestinal tissue injury scores of groups according to Chiu et al.

\begin{tabular}{|lcccc|}
\hline \multirow{2}{*}{$\begin{array}{l}\text { Number } \\
\text { of rats }\end{array}$} & C & S & I/R & I/R + S \\
\hline 1 & 0 & 0 & 4 & 2 \\
\hline 2 & 0 & 0 & 2 & 1 \\
\hline 3 & 0 & 0 & 5 & 1 \\
\hline 4 & 0 & 0 & 3 & 1 \\
\hline 5 & 0 & 0 & 2 & 2 \\
\hline 6 & 0 & 0 & 2 & 1 \\
\hline 7 & 0 & 0 & 3 & 1 \\
\hline 8 & 0 & 0 & 4 & 2 \\
\hline C- control, S - sesamin, I/R - ischemia/reperfusion, \\
I/R+ S - ischemia reperfusion + sesamin.
\end{tabular}

the plasma values. In this respect, it differs from other studies.

In another study of Loffredo et al. [31] it hast been shown that nitrate (NOX2) upregulation is associated with arterial dysfunction in patients with peripheral artery disease (PAD). In this study, they have used propionyl-L-carnitine (PLC) to estimate if it has a protective effect on oxidative stress-mediated mechanism. In order to evaluate
Table V. Histopathologic evaluation of intestinal tissue for each group (mean \pm SD)

\begin{tabular}{|c|c|c|c|c|c|}
\hline & \multicolumn{5}{|c|}{ Group $(n=8)$} \\
\hline & $\mathrm{C}$ & $\mathrm{S}$ & I/R & $\mathrm{I} / \mathrm{R}+\mathrm{S}$ & $P$-value \\
\hline $\begin{array}{l}\text { Intestinal } \\
\text { tissue injury } \\
\text { score }\end{array}$ & $\begin{array}{c}0.00 \\
\pm 0.00\end{array}$ & $\begin{array}{c}0.00 \\
\pm 0.00\end{array}$ & $\begin{array}{c}2.75 \\
\pm 0.25^{1}\end{array}$ & $\begin{array}{c}1.38 \\
\pm 0.18\end{array}$ & 0.001 \\
\hline
\end{tabular}

$S$ - standard deviation, $C$ - control, $S$ - sesamin, I/R - ischemial reperfusion, $I / R+S-$ ischemia reperfusion + sesamin, $p$-values indicates the differences between the groups (Kruskal-Wallis test) ${ }^{I} I / R>C, S, I / R+S($ Mann-Whitney $U$ test, $p<0.005)$.

this, they have measured the NOX2 activity, which is the catalytic core of nicotinamide adenine dinucleotide phosphate (NADPH) oxidase. In addition, it is well known that NADPH oxidase is the most important producer of reactive oxidant species (ROS). Eventually, they have shown that PLC used in PAD patients improves post-ischemic flow and revascularization via down regulation of NOX2 generation oxygen free radicals, and also upregulates inducible nitric oxide (NO) synthase at the level of endothelial cells [32]. Kertmen et al. [33] conducted a study by using tetracosactide, which is a synthetic analogy of adrenocorticotropic hor- 
mone on the rabbits, to see the protective effect of tetracosactide on spinal ischemia reperfusion injury. In order to evaluate reactive oxidant species, they have measured myeloperoxidase levels. They have seen that tetracosactide shows significant neuroprotective activity against ischemia-reperfusion injury of the spinal cord. Although we could not measure the reactive oxidant species such as myeloperoxidase and NADPH oxidase in our study, we believe that sesamin may have similar mechanism like PLC on intestinal tissue ischemia reperfusion injury. It may be seen as a limitation of our study, but at the same time, we believe that in the light of our research, new studies may be designed to investigate the effect of sesamin on NADPH oxidase and other reactive oxidant species.

In a study conducted by Zhang et al. [34] with spontaneous hypertensive rats, it has been shown that sesamin improves arterial dysfunction via down regulation of NADPH oxidase subunit; the antioxidant effect of sesamin is emphasized. In our study, both plasma and tissue TAS levels were significantly higher in the sesamin-treated groups, especially in the IR + S group than in the other groups. In this respect, it is thought that sesamin may be effective in reducing oxidative damage by increasing plasma and tissue TAS levels. Study of Li et al. [35] presented sesamin with its protective effect on tissue damage in the experimental renal ischemia reperfusion model. In our study, histopathological evaluation revealed that cellular damage was significantly lower in the $I / R+S$ group compared to the I/R group. In another study of Cheng et al. [36] it has been shown that oral sesamin therapy has a markedly neuroprotective effect on the experimental cerebral ischemia model. Histopathologic evaluation of our study also showed much better histopathologic results in the IR + S group compared to the I/R group. This suggests that sesamin has a protective effect on bowel mucosa. Another characteristic feature of our study is that TAS, TOS, and OSI values were not assessed only on plasma but also on intestinal tissue affected by ischemia-reperfusion. As a result, in our study, we have found that sesamin increases tissue TAS levels and reduces TOS levels as well as protects the tissue against I/R damage.

In conclusion, the findings obtained showed that sesamin helps to protect the intestinal tissue at the cellular level by reducing the oxidative stress and inflammation both the plasma and tissue levels in the experimental ischemia reperfusion model.

\section{Acknowledgments}

The authors would like to thank Dr. Esin Secgin Sayhan for statistical analysis.

\section{Conflict of interest}

The authors declare no conflict of interest.

\section{References}

1. Megison SM, Horton JW, Chao H, Walker PB. A new model for intestinal ischemia in the rat. J Surg Res 1990; 49: 168-73.

2. Savaş C, Aras T, Cakmak M, et al. Pentoxifylline inhibits overflow and reduces intestinal reperfusion injury. J Pediatr Surg 1997; 32: 905-10.

3. Tapuria N, Kumar Y, Habib MM, Amara MA, Seifalian AM, Davidson BR. Remote ischemic preconditioning: a novel protective method from ischemia reperfusion injury a review. J Surg Res 2008; 150: 304-30.

4. Jamieson WG, Pliagus G, Marchuk S, et al. Effect of antibiotic and fluid resuscitation upon survival time in experimental intestinal ischemia. Surg Gynecol Obstet 1988; 167: 103-8.

5. Schoenberg MH, Beger HG. Oxygen radicals in intestinal ischemia and reperfusion. Crit Care Med 1988; 10: 947-53.

6. Tisi P, Shearman CP. Systemic consequences of reperfusion injury. In: Ischaemia-Reperfusion Injury. Blackwell Science, London 1999; 20-30.

7. Hernandez LA, Grisham MB, Twohig B, Arfors KE, Harlan JM, Granger DN. Role of neutrophils in ischemia-reperfusion-induced microvascular injury. Am J Physiol 1987; 253: 699-703.

8. Offord E, Van Poppel G, Tyrrell R. Markers of oxidative damage and antioxidant protection: current status and relevance to disease. Free Radic Res 2000; 33: 5-19.

9. Mallick IH, Yang W, Winslet MC, Seifalian AM. Ischemia-reperfusion injury of the intestine and protective strategies against injury. Dig Dis Sci 2004; 49: 1359-77.

10. Bedigian D, Harlan JR. Evidence for cultivation of sesame in the ancient world. Econ Bot 1986; 40: 137-54.

11. Wan Y, Li H, Fu G, Chen X, Chen F, Xie M. The relationship of antioxidant components and antioxidant activity of sesame seed oil. J Sci Food Agric 2015; 95: 2571-8.

12. Farhoosh R, Tavassoli-Kafrani MH, Sharif A. Antioxidant activity of sesame, rice bran and bene hull oils and their unsaponifiable matters. Eur J Lipid Sci Technol 2011; 113: 506-12.

13. Liu CM, Zheng GH, Ming QL. Sesamin protects mouse liver against nickel-induced oxidative DNA damage and apoptosis by the PI3K-Akt pathway. J Agric Food Chem 2013; 61: 1146-54.

14. Bournival J, Francoeur MA, Renaud J, Martinoli MG. Quercetin and sesamin protect neuronal PC12 cells from high-glucose induced oxidation, nitrosative stress, and apoptosis. Rejuvenation Res 2012; 15: 322-33.

15. Lee CC, Liu KJ, Wu YC. Sesamin inhibits macrophageinduced vascular endothelial growth factor and matrix metalloproteinase-9 expression and proangiogenic activity in breast cancer cells. Inflammation 2011; 34: 209-21.

16. Abou-Gharbia HA, Shahidi F, Shehata AAY, Youssef MM. Oxidative stability of extracted sesame oil from raw and processed seeds. J Food Lipids 1996; 3: 59-72.

17. Erel O. A novel automated method to measure total antioxidant response against potent free radical reactions. Clin Biochem 2004; 37: 112-9.

18. Erel O. A new automated colorimetric method for measuring total oxidant status. Clin Biochem 2005; 38 : 1103-11. 
19. Aycicek A, Erel O, Kocyigit A. Increased oxidative stress in infants exposed to passive smoking. Eur J Pediatr 2005; 164: 775-8.

20. Chiu CJ, McArdle AH, Brown R, et al. Intestinal mucosal lesion in low-flow states. I. A morphological, hemodynamic, and metabolic reappraisal. Arch Surg 1970; 101: 478-83.

21. Pirincci PA, Bolkent S. The role of epidermal growth factor in prevention of oxidative injury and apoptosis induced by intestinal ischemia/reperfusion in rats. Acta Histochem 2014; 116: 167-75.

22. El Assal ON, Besner GE. Heparin-binding epidermal growth factor-like growth factor and intestinal ischemia-reperfusion injury. Semin Pediatr Surg 2004; 13: 2-10.

23. Martin AE, Luquette MH, Besner GE. Timing, route, and dose of administration of heparin-binding epidermal growth factor-like growth factor in protection against intestinal ischemia-reperfusion injury. J Pediatr Surg 2005; 40: 1741-7.

24. Schoenberg MH, Beger HG. Reperfusion injury after intestinal ischemia. Crit Care Med 1993; 21: 1376-86.

25. Rabus M, Demirbag R, Sezen Y, et al. Plasma and tissue oxidative stress index in patients with rheumatic and degenerative heart valve disease. Turk Kardiyol Dern Ars 2008; 36: 536-40.

26. Sağıroğlu T, Oğuz S, Sağıroğlu G, et al. The effects of apelin on mesenteric ischemia and reperfusion damage in an experimental rat model. Balkan Med J 2012; 29: 148-52.

27. Martinez JP, Hogan GJ. Mesenteric ischemia. Emerg Med Clin North Am 2004; 22: 909-28.

28. Chatterjee PK. Novel pharmacological approaches to the treatment of renal ischemia-reperfusion injury: a comprehensive review. Naunyn Schmiedebergs Arch Pharmacol 2007; 376: 1-43.

29. Akcilar R, Akcilar A, Savran B. Effects of Ukrain in rats with intestinal ischemia and reperfusion. Int J Clin Exp Med 2015; 15: 22158-66.

30. Torun E, Gedik AH, Cakir E, et al. Serum paraoxonase, TAS, TOS and ceruloplasmin in brucellosis. Int J Clin Exp Med 2014; 7: 1592-7.

31. Loffredo L, Carnevale R, Cangemi R, et al. NOX2 up-regulation is associated with artery dysfunction in patients with peripheral artery disease. Int J Cardiol 2013; 165 : 184-92.

32. Dikalova AE, Góngora MC, Harrison DG, et al. Upregulation of Nox1 in vascular smooth muscle leads to impaired endothelium-dependent relaxation via eNOS uncoupling. Am J Physiol Heart Circ Physiol 2010; 299: 673-9.

33. Kertmen H, Celikoglu E, Ozturk OC, et al. Comparative effects of methylprednisolone and tetracosactide (ACTH) on ischemia/reperfusion injury of the rabbit spinal cord. Arch Med Sci 2018; 14: 1459-70.

34. Zhang JX, Yang JR, Chen GX, et al. Sesamin ameliorates arterial dysfunction in spontaneously hypertensive rats via downregulation of NADPH oxidase subunits and upregulation of eNOS expression. Acta Pharmacol Sin 2013; 34: 912-20.

35. Li K, Gong X, Kuang G, et al. Sesamin protects against renal ischemia reperfusion injury by promoting CD39-adenosine-A2AR signal pathway in mice. Am J Transl Res 2016; 8: 2245-54.

36. Cheng FC, Jinn TR, Hou RC, et al. Neuroprotective effects of sesamin and sesamolin on gerbil brain in cerebral ischemia. Int J Biomed Sci 2006; 2: 284-8. 